\title{
Renal involvement in Henoch-Schönlein purpura: a multivariate analysis of initial prognostic factors
}

\author{
José Luiz J. de Almeida, ${ }^{1}$ Lúcia Maria A. Campos, ${ }^{2}$ Luciana B. Paim, ${ }^{3}$ \\ Claudio Leone, 4 Vera Hermínia K. Koch, ${ }^{5}$ Clovis Artur A. Silva6
}

\begin{abstract}
Objectives: To identify initial predictive factors of renal involvement in children and adolescents with Henoch-Schönlein purpura.

Methods: We reviewed the medical records of 142 patients admitted to our University Hospital over a 21-year period with a diagnosis of Henoch-Schönlein purpura. The initial predictive factors assessed, observed during the first 3 months, included: demographic data, clinical manifestations (persistent palpable purpura, arthritis, abdominal pain, severe abdominal pain, gastrointestinal bleeding, orchitis, central nervous system involvement and pulmonary hemorrhage), laboratory tests (serum IgA levels) and treatment given (corticosteroids, intravenous immunoglobulin and immunosuppressive drugs). Patients were divided into two groups (presence or absence of nephritis) and assessed by univariate and multivariate analysis.

Results: Evidence of nephritis was detected in 70 patients (49.3\%). The univariate analysis revealed that severe abdominal pain $(p=0.0049 ; O R=1.6 ; 95 \% C I 1.18-2.21)$, gastrointestinal bleeding $(p=0.004 ; O R=1.6 ; 95 \% C I$ 1.10-2.26) and corticosteroid use ( $p=0.0012 ; O R=1.7 ; 95 \%$ CI $1.28-2.40)$ were all associated with increased incidence of renal involvement. In the multivariate analysis, logistic regression demonstrated that the only independent variable that predicted nephritis was intense abdominal pain $(p<0.012 ; O R=2.593 ; 95 \% C I$ 1.234-5.452).

Conclusions: Severe abdominal pain was a significant predictor of nephritis in Henoch-Schönlein purpura. Consequently, pediatric patients exhibiting this clinical manifestation should be rigorously monitored, due to the increased risk of renal involvement.
\end{abstract}

J Pediatr (Rio J). 2007;83(3):259-266: Henoch-Schönlein purpura, nephritis, children, kidney disease, prognosis.

1. Acadêmico de Medicina (5ำ ano), Faculdade de Medicina, Universidade de São Paulo (USP), São Paulo, SP, Brasil.

2. Doutora, Faculdade de Medicina, USP, São Paulo, SP, Brasil. Médica assistente, Unidade de Reumatologia Pediátrica, Instituto da Criança, Hospital das Clínicas, Faculdade de Medicina, USP, São Paulo, SP, Brasil.

3. Médica, Complementação Especializada, Unidade de Reumatologia Pediátrica, Instituto da Criança, Hospital das Clínicas, Faculdade de Medicina, USP, São Paulo, SP, Brasil.

4. Professor livre-docente, Departamento de Pediatria, Faculdade de Medicina, USP, São Paulo, SP, Brasil. Núcleo de Consultoria e Apoio em Metodologia de Pesquisa e Estatística, Departamento de Pediatria, Faculdade de Medicina, USP, São Paulo, SP, Brasil.

5. Professora colaboradora, Departamento de Pediatria, Faculdade de Medicina, USP, São Paulo, SP, Brasil. Doutora, Faculdade de Medicina, USP, São Paulo, SP, Brasil. Responsável, Unidade de Nefrologia Pediátrica, Instituto da Criança, Hospital das Clínicas, Faculdade de Medicina, USP, São Paulo, SP, Brasil.

6. Professor colaborador, Departamento de Pediatria, Faculdade de Medicina, USP, São Paulo, SP, Brasil. Doutor, Faculdade de Medicina, USP, São Paulo, SP, Brasil. Responsável, Unidade de Reumatologia Pediátrica, Instituto da Criança, Hospital das Clínicas, Faculdade de Medicina, USP, São Paulo, SP, Brasil.

Manuscript received Oct 30 2006, accepted for publication Jan 172007.

Suggested citation: de Almeida JL, Campos LM, Paim LB, Leone C, Koch VH, Silva CA. Renal involvement in Henoch-Schönlein purpura: a multivariate analysis of initial prognostic factors. J Pediatr (Rio J). 2007;83(3):259-266.

doi 10.2223/JPED.1638 


\section{Introduction}

Henoch-Schönlein purpura (HSP), also known as anaphylactic purpura, nonthrombocytopenic purpura, rheumatic purpura or allergic purpura, is the most common type of vasculitis in the pediatric age group. ${ }^{1-3}$ It is characterized by cutaneous, articular, gastrointestinal and renal involvement, while orchitis, vasculitis of the central nervous system (CNS) and pulmonary hemorrhage are rare findings. ${ }^{2}$ The most characteristic clinical manifestation, and one which is found in all patients, is non-thrombocytopenic palpable purpura, symmetrically located and with a preference for the lower limbs and buttocks. ${ }^{1-3}$

Kidney damage is the principal prognostic determinant in HSP, affecting between 10 and $50 \%$ of patients. ${ }^{4-7}$ The most common renal alterations are transitory hematuria and proteinuria, commonly with duration of less than 1 month. ${ }^{1}$ Of those children who do continue to suffer from these urinary sediment alterations beyond the first month of the disease, around $30 \%$ exhibit complete recovery by the third month, rarely progressing with persistent hematuria and/or proteinuria or nephritic or nephrotic syndromes. ${ }^{1,2}$ While prognosis is habitually favorable, patients with nephritis may progress to renal insufficiency. ${ }^{8}$

There is a scarcity of studies of pediatric HSP patients employing multivariate analysis models that have evaluated the initial prognostic factors associated with renal involvement, ${ }^{4-7}$ and those that do exist generally investigate oriental populations. ${ }^{4,5}$ Furthermore, these studies do not describe other initial alterations of this disease, such as orchitis, CNS vasculitis and pulmonary hemorrhage.

This being so, the objectives of this study were to evaluate renal involvement in patients with HSP and to identify initial factors, assessed during the first 3 months, that are predictive of nephritis, based on demographic data, clinical characteristics, laboratory test results and the treatment given to these patients.

\section{Methods}

The medical records of all 189 children and adolescents who were seen during a 21-year period (January, 1983 to December, 2003) and were diagnosed with HSP were retrospectively analyzed in accordance with a clinical and laboratory protocol. All of these patients met the American College of Rheumatology classification criteria for a diagnosis of HSP: the presence of two or more of four criteria in patients with palpable purpura (Table 1$).{ }^{9}$ All of these patients were seen at the Children's Institute ( $\mathrm{ICr}$ - Instituto da Criança) part of the Hospital das Clínicas ( $\mathrm{HC})$, affiliated to the Faculdade de Medicina, Universidade de São Paulo (FMUSP). At our University Hospital, all patients with HSP seen at the infirmary and emergency room, irrespective of disease severity and manifestations, were promptly assessed by the physicians at the Rheumatology and/or Pediatric Nephrology Departments of the ICr-HC-FMUSP, and were followed-up at these departments' clinics. This study was approved by the Research Ethics Committee at the HC-FMUSP.

The protocol covered evaluation of demographic data, clinical manifestations, laboratory findings and HSP treatments, such as cutaneous, articular and gastrointestinal involvement, orchitis, CNS involvement, pulmonary hemorrhage, elevated serum IgA, treatment with corticosteroids, immunosuppressive drugs or intravenous gammaglobulin.

According to other studies in the medical literature, ${ }^{4,5,10}$ HSP renal involvement or nephritis can be defined as the

Table 1 - Criteria for Henoch-Schönlein purpura classification ${ }^{9}$

\begin{tabular}{ll}
\hline Criteria & Definitions \\
\hline Palpable purpura & Raised purpura, not related to thrombocytopenia \\
Age $<20$ at onset & Patient 20 years or younger at onset of first symptoms \\
Bowel angina & Diffuse abdominal pain, worse after meals, or intestinal bleeding \\
Altered cutaneous biopsy findings & Histology with evidence of granulocytes in the walls of arterioles or venules \\
\end{tabular}


presence of one or more of the following alterations: hematuria ( $>5$ red blood cells per microscopic field), proteinuria ( $>0.1 \mathrm{~g} / \mathrm{m}^{2} /$ day), ${ }^{5}$ renal insufficiency (creatinine clearance $>80 \mathrm{~mL} / \mathrm{min} / 1.73 \mathrm{~m}^{2}$ ), nephrotic syndrome (edema, serum albumin $>2.5 \mathrm{~g} / \mathrm{L}$ and proteinuria $>1 \mathrm{~g} / \mathrm{m}^{2} /$ day). ${ }^{10}$ Kidney biopsies were indicated, in particular for patients with renal insufficiency or nephrotic syndrome. Histology results were assessed according to the International Study of Kidney Disease in Children, and classified into one of six subtypes: grade I (normal, or discrete alterations), grade II (proliferative mesangial glomerulonephritis), grade III (proliferative mesangial glomerulonephritis with crescents in less than $50 \%$ of glomeruli), grade IV (proliferative mesangial glomerulonephritis with crescents in 50 to $75 \%$ of glomeruli), grade $\mathrm{V}$ (proliferative mesangial glomerulonephritis with crescents more than $75 \%$ of glomeruli) and grade VI (membranoproliferative glomerulonephritis).

In order to identify initial prognostic factors (present within the first 3 months of the disease) associated with renal involvement (initial or progressive), patients were divided into two groups: with or without nephritis. The two groups were then compared on the basis of the following initial variables: demographic data (sex and age at disease onset), clinical characteristics (persistent palpable purpura lasting for more than 1 month after disease onset, arthritis, abdominal pain, gastrointestinal bleeding, orchitis, CNS involvement or pulmonary hemorrhage), elevated serum IgA during the first month of the disease ( $>255 \mathrm{mg} / \mathrm{dL}$ ), use of corticosteroids, immunosuppressors or intravenous gammaglobulin.

Abdominal pain was defined as mild (pain improves with paracetamol) or severe (abdominal angina, with diffuse abdominal pain that make eating impossible ${ }^{7}$ and/or gastrointestinal bleeding ${ }^{4,9}$ ). Patients with severe abdominal pain either did not tolerate or did not respond to paracetamol. Abdominal or testicular with Doppler ultrasound was employed to confirm diagnoses of intussusception or orchitis, respectively. This is important for ruling out orchitis secondary to vasculitis of the spermatic cord, which is rarely observed in $\mathrm{HSP}^{2}$

Corticosteroids, employed during the first 3 months of HSP, were indicated for treatment of severe gastrointestinal involvement (severe abdominal pain and/or intestinal bleeding), orchitis or nephritis (nephrotic syndrome and/or renal insufficiency). Prednisone or prednisolone were administered at a dosage of $2 \mathrm{mg} / \mathrm{kg} /$ day for 1 week and later reduction between 3 and 4 weeks or pulse therapy with methylprednisolone at a dosage of $30 \mathrm{mg} / \mathrm{kg} /$ day (maximum of $1 \mathrm{~g} /$ day for 3 days), followed by prednisone or prednisolone as described above. Immunosuppressors, particularly intravenous pulse therapy with cyclophosphamide ( 0.5 to
$1 \mathrm{~g} / \mathrm{m}^{2} /$ month) during the first 3 months of HSP, were indicated for patients with renal insufficiency or nephrotic syndrome who did not respond to pulse therapy with methylprednisolone. Intravenous gammaglobulin $(2 \mathrm{~g} / \mathrm{kg} / \mathrm{in}$ a single dose) was administered during the first 3 months of HSP to patients with severe gastrointestinal involvement (severe abdominal pain and/or intestinal bleeding) who did not respond to pulse therapy with methylprednisolone. ${ }^{2,3}$

Univariate statistical analysis was carried out using Fisher's exact test and the chi-square test to compare demographic data, clinical characteristics, serum IgA levels and treatment between the two study groups (with or without nephritis). Student's t test for independent samples was used to compare mean age at onset. Multivariate analysis employed backward stepwise logistic regression. Independent variables that had statistical significance of $5 \%$, or close to this figure, after univariate analysis were chosen for the multivariate analysis. In the regression model the dependent variable was presence of nephritis, and independent variables were persistent purpura, abdominal pain, severe abdominal pain and gastrointestinal bleeding. For all statistical tests the level of significance was defined as $5 \%$.

\section{Results}

A total of 189 patients with HSP were treated during the 21-year period, and of these 142 patients were included in the study as their medical records provided complete data.

The principal clinical characteristics, laboratory tests and treatment of these patients with HSP are listed in Table 2. Forty-six percent of these 142 patients were male, $100 \%$ had palpable purpura, $28 \%$ persistent palpable purpura during the first month of the disease, $69 \%$ had arthritis, $62 \%$ abdominal pain, $49 \%$ nephritis, $32 \%$ severe abdominal pain, $10 \%$ gastrointestinal bleeding, $9 \%$ orchitis (painful, acute scrotal edema associated with palpable purpuric lesions), and one patient $(0.7 \%)$ suffered a cerebral vascular accident due to vasculitis of the CNS. None of the patients suffered pulmonary hemorrhage. Elevated serum IgA levels occurred in $43 \%$ (Table 2).

Forty-six patients (32\%) were given corticosteroids during the first 3 months of their HSP, which were indicated for severe gastrointestinal involvement in isolation in 38 cases (31\%), severe gastrointestinal involvement associated with orchitis in six $(9 \%)$, abdominal invagination, nephrotic syndrome, acute renal insufficiency and cerebral vascular accident due to vasculitis of the CNS in one case $(0.7 \%)$ and for nephrotic syndrome with acute renal insufficiency in another $(0.7 \%)$. These two patients $(1.4 \%)$ with nephrotic syndrome and renal insufficiency (renal biopsy showing grade IV glomerulonephritis) required pulse therapy with intravenous cyclophosphamide, and two others (1.4\%) with intestinal bleeding were given intravenous gammaglobulin. 
All 70 patients with nephritis had isolated hematuria or proteinuria (31 and $7 \%$, respectively) or both ( $11 \%$ ), two had nephrotic syndrome (1\%) and two had renal insufficiency (1\%) (Table 2). Nephritis occurred during the first 3 months of the disease in $69.98 \%$ of these 70 patients, and just one patient $(2 \%)$ developed late-onset nephritis (acute renal insufficiency, hematuria and proteinuria, with renal biopsy demonstrating grade III glomerulonephritis) after 3 years' follow-up.

Table 3 contains the univariate analysis of prognostic factors associated with renal involvement in HSP. Patients with nephritis exhibited a significantly greater frequency of intense abdominal pains, gastrointestinal bleeding and corticosteroid use compared with the patients with no renal involvement ( 43 vs. $21 \%, p=0.004, \mathrm{OR}=1.62,95 \% \mathrm{CI}$ $1.18-2.21 ; 16$ vs. $5 \%, \mathrm{p}=0.049, \mathrm{OR}=1.57,95 \% \mathrm{CI}$ $1.10-2.26$; and 44 vs. $21 \%, p=0.0012, \mathrm{OR}=1.75,95 \% \mathrm{CI}$ 1.28-2.40, respectively) (Table 3 ). There was also an increased tendency for patients with abdominal pain to develop nephritis than for patients without this manifestation (70 vs. $54 \%, p=0.059$ ).

Nevertheless, there was no statistical difference between patients with and without nephritis in terms of male sex (50 vs. $43 \%, p=0.5)$, age at onset of HSP above 4 or 7 years ( 83 vs. $71 \%, p=0.311 ; 43$ vs. $36 \%, p=0.6$, respectively), mean \pm standard deviation of age at disease onset $(6.7 \pm 2.9$ vs. $6.1 \pm 3.0$ years, $p=0.247$ ), persistent purpura during the first month of the disease, arthritis, orchitis and CNS vasculitis

Table 2 - Clinical characteristics, laboratory tests and treatment of 142 patients with Henoch-Schönlein purpura

\begin{tabular}{|c|c|}
\hline Characteristics $(n=142)$ & n (\%) \\
\hline Male & $66(46)$ \\
\hline Palpable purpura & $142(100)$ \\
\hline Persistent palpable purpura & $40(28)$ \\
\hline Arthritis & $98(69)$ \\
\hline Abdominal pain & $88(62)$ \\
\hline Severe abdominal pain & $45(32)$ \\
\hline Gastrointestinal bleeding & $15(10)$ \\
\hline Renal involvement & $70(49)$ \\
\hline Hematuria in isolation & $44(31)$ \\
\hline Proteinuria in isolation $>0.1 \mathrm{~g} / \mathrm{m}^{2} /$ day & $10(7)$ \\
\hline Hematuria associated with proteinuria $>0.1 \mathrm{~g} / \mathrm{m}^{2} / \mathrm{day}$ & $16(11)$ \\
\hline Nephrotic syndrome & $2(1)$ \\
\hline Renal insufficiency acute & $2(1)$ \\
\hline Orchitis & $6(9.1)$ \\
\hline Cerebral vascular accident & $1(0.7)$ \\
\hline Pulmonary hemorrhage & 0 \\
\hline Elevated serum IgA ( $>255$ mg/dL, $n=69$ ) & $30(43)$ \\
\hline Given corticosteroids & $46(32)$ \\
\hline Given immunosuppressors & $2(1.4)$ \\
\hline Given intravenous gammaglobulin & $2(1.4)$ \\
\hline
\end{tabular}


( 33 vs. $24 \%, p=0.2 ; 66$ vs. $72 \%, p=0.469 ; 11$ vs. $6 \%, p=$ $0.676 ; 1$ vs. $0 \%, p=0.493$, respectively), elevated serum IgA (14 vs. $29 \%, p=0.809)$ or treatment with immunosuppressors or intravenous gammaglobulin (1 vs. $0 \%, p=0.493 ; 1$ vs. $0 \%, p=0.493$, respectively) (Table 3 ).

The only variable independently associated with nephritis according to the multivariate analysis logistic regression model was presence of severe abdominal pain ( $p<0.012$; OR $=2.593 ; 95 \%$ CI 1.234-5.452; Nagelkerke's $\left.R^{2}=0.061\right)$ (Table 4).

\section{Discussion}

Kidney damage is the principal determinant of prognosis in HSP and occurs in between 10 and $50 \%$ of cases, predominantly among preschool children and schoolchildren with mean age of disease onset of 6 years, ${ }^{1-7}$ in common with our study. The majority of these children develop nephritis during the first 3 weeks of the disease, ${ }^{2}$ and it is uncommon for an initial renal injury to appear after other clinical manifestations have disappeared, as can be observed in $98 \%$ of our patients.

The remaining manifestations of HSP identified in the present study were similar to those found in the medical literature: palpable purpura $(100 \%)$, persistent palpable purpura during the first month of the disease (22 to $62 \%$ ), arthritis ( 50 to $74 \%$ ), abdominal pain ( 55 to $72 \%$ ), severe abdominal pain ( 15 to $60 \%$ ), gastrointestinal bleeding ( 8.8 to $24 \%$ ) and orchitis (2 to $32 \%) \cdot{ }^{1-7}$ In contrast, CNS involvement with cerebral vasculitis has rarely been described, ${ }^{11}$ as was observed in just one of our patients.

Table 3 - Univariate analysis of prognostic factors in 142 patients associated with renal involvement in Henoch-Schönlein purpura

\begin{tabular}{|c|c|c|c|}
\hline $\begin{array}{l}\text { Prognostic factors, } \\
n=142(\%)\end{array}$ & $\begin{array}{l}\text { With nephritis } \\
\quad(n=70)\end{array}$ & $\begin{array}{l}\text { Without nephritis } \\
\qquad(n=72)\end{array}$ & $\begin{array}{c}\text { p, OR } \\
(95 \% C I)\end{array}$ \\
\hline Male sex & $35(50)$ & $31(43)$ & 0.500 \\
\hline Age at onset $>4$ years & $58(83)$ & $51(71)$ & 0.311 \\
\hline Age at onset $>7$ years & $30(43)$ & $26(36)$ & 0.600 \\
\hline $\begin{array}{l}\text { Age at onset, } \\
\text { mean in years } \pm \text { SD (variation) }\end{array}$ & $\begin{array}{l}6.7 \pm 2.9 \\
(2-14.3)\end{array}$ & $\begin{array}{l}6.1 \pm 3.0 \\
(1.1-12.8)\end{array}$ & 0.247 \\
\hline Persistent purpura & $23(33)$ & $17(24)$ & 0.200 \\
\hline Arthritis & $46(66)$ & $52(72)$ & 0.469 \\
\hline Abdominal pain & $49(70)$ & $39(54)$ & 0.0589 \\
\hline Severe abdominal pain & $30(43)$ & $15(21)$ & $\begin{array}{l}0.0048,1.62 \\
(1.18-2.21)\end{array}$ \\
\hline Gastrointestinal bleeding & $11(16)$ & $4(5)$ & $\begin{array}{l}0.049,1.57 \\
(1.10-2.26)\end{array}$ \\
\hline Orchitis & $4(11)$ & $2(6)$ & 0.676 \\
\hline Vasculitis of the CNS & $1(1)$ & 0 & 0.493 \\
\hline $\begin{array}{l}\text { Elevated serum IgA } \\
(>255 \mathrm{mg} / \mathrm{dL}, \mathrm{n}=69)\end{array}$ & $10(14)$ & $20(29)$ & 0.089 \\
\hline Use of corticosteroids & $31(44)$ & $15(21)$ & $\begin{array}{l}0.0012-1.75 \\
(1.28-2.40)\end{array}$ \\
\hline Use of immunosuppressors & $2(1)$ & 0 & 0.241 \\
\hline Use of IVGG & $2(1)$ & 0 & 0.241 \\
\hline
\end{tabular}

$95 \% \mathrm{CI}=95 \%$ confidence interval; CNS = central nervous system; IVGG = intravenous gammaglobulin; OR = odds ratio; SD = standard deviation. 
One feature of this study population is that all patients with HSP seen at our Hospital, even those presenting with mild forms of the disease, were invariably treated by the Rheumatology and/or Pediatric Nephrology departments. These patients were seen at the various clinics and the emergency room concomitantly by general pediatricians and specialists (rheumatologists and/or pediatric nephrologists).

Just four studies have assessed initial risk factors for nephritis of HSP using univariate and multivariate analysis models, and three of these were undertaken in oriental countries (Japan and Korea). In these studies nephritis occurred in between 21 and $49 \%$ of cases, ${ }^{4-7}$ which is comparable with our study.

Kaku et al. $^{4}$ found evidence that abdominal pains of severe intensity, persistent purpura, age over 7 years and reduced serum coagulation factor XIII levels were initial risk factors associated with HSP nephritis. Sano et al. ${ }^{5}$ assessed 134 patients with HSP and used univariate analysis to determine that significant abdominal pain, persistent purpura and treatment with corticosteroids were most associated with nephritis of HSP. The third study, undertaken by Rigante et al., ${ }^{6}$ demonstrated that the presence of persistent purpura ( $>1$ month) and severe abdominal pain at the start of the HSP clinical picture were also associated with increased kidney damage on univariate analysis. A second analysis, employing logistic regression, revealed that persistent purpura was the only factor that remained associated with nephritis of HSP and that it also increased the chances of recurrent kidney disease. In a recent study, Shin. et al. ${ }^{7}$ evaluated 94 patients with HSP and also found evidence that the presence of persistent purpura and intense abdominal pains at disease onset had a significant relationship with renal involvement.

In our paper it has been demonstrated that by univariate analysis severe abdominal pain, gastrointestinal bleeding and use of corticosteroids were factors associated with nephritis. However, when a logistic regression model was constructed, it was revealed that only severe abdominal pain were an independent variable with significance for predicting nephritis. Nevertheless, it is worth pointing out that significant abdominal pain was practically the only factor associated with nephritis in common with all the other studies. ${ }^{4-7}$ the definition of severe abdominal pain adopted here was similar to that of other studies in the literature, ${ }^{4,7}$ and all of the patients presenting this manifestation required corticosteroids, emphasizing the severity of this development.

There is considerable disagreement in published literature with relation to early introduction of corticosteroids and reduced frequency of nephritis in HSP. 4,5,12,13 Mollica et al., ${ }^{12}$ in a prospective, randomized study, found that early introduction of $1 \mathrm{mg} / \mathrm{kg} /$ day of prednisone for 2 weeks reduced the incidence of nephritis. Similarly, Kaku et al. ${ }^{4}$ demonstrated that treatment with corticosteroids reduced the risk of nephritis, with a low relative risk of 0.36 . However, other authors have failed to demonstrated any reduction in the course of HSP nephritis with early introduction of corticosteroids. ${ }^{5,13}$ Other randomized and placebocontrolled trials have also found that the use of prednisone at the start of HSP does not avert kidney damage. ${ }^{14,15}$ In our patients sample it was demonstrated that use of corticosteroids was associated with greater renal involvement, since these patients exhibited a greater frequency of severe gastrointestinal involvement and required these medications. These were habitually introduced during the first month of the disease and were predominantly indicated to control significant gastrointestinal manifestations, such as intermittent and severe abdominal pain in colic, and bleeding and intussusception.

Table 4 - Multivariate analysis by logistic regression of prognostic factors in 142 patients associated with renal involvement in Henoch-Schönlein purpura

\begin{tabular}{lcccc}
\hline Dependent variable & Independent variable & OR (95\%CI) & Nagelkerke's R $^{\mathbf{2}}$ & P \\
\hline Nephritis & Severe abdominal pain & $2.593(1.234-5.452)$ & 0.061 & $<0.012$ \\
\hline
\end{tabular}

$95 \% \mathrm{CI}=95 \%$ confidence interval $; \mathrm{OR}=$ odds ratio. 
Studies have also been carried out of early laboratory markers associated with nephritis of HSP. Elevated serum IgA levels can be observed in 20 to $50 \%$ of patients with HSP, during the first 3 months of the disease, tending to normalize later. ${ }^{1-3}$ Rheumatoid factor IgA (RF-IgA) can be detected in around $50 \%$ of cases, without correlation with severity or duration of the disease. ${ }^{16}$ Similarly, some authors have reported that the presence of circulating IgA-immune complexes, ${ }^{17}$ IgG perinuclear antineutrophil cytoplasmic antibodies and IgA antineutrophil cytoplasmic antibodies (IgG P-ANCA and IgA ANCA, respectively) ${ }^{18,19}$ are associated with increased renal involvement during the acute phase of the disease. Notwithstanding, our results did not demonstrate any association between serum IgA levels and the occurrence of nephritis. Furthermore, other authors suggest that serum IgD levels are elevated in patients with HSP who do not have nephritis and low in those patients who do; with no correlation with serum IgA levels. ${ }^{20}$

The etiopathogenesis of HSP remains unknown. It is, however, known that a combination of several factors, in genetically predisposed patients, favor the alterations to immunoregulatory mechanisms that are responsible for the manifestations of this disease, ${ }^{2}$ and that different populations are likely to differ, which could possibly explain the higher prevalence rates in oriental countries. More recently, attempts have been made to predict nephritis by means of genetic polymorphism studies. ${ }^{21,22}$ In a study carried out by Yi et al., ${ }^{21}$ the presence of a polymorphism in the PAX2 gene (a gene which is involved in renal maturation) was not associated with the occurrence of HSP, but did increase genetic susceptibility to nephritis. Additionally, a study conducted by Ozkaya et al. ${ }^{22}$ demonstrated that a polymorphism of the renin-angiotensin system gene was associated with a 3.5 times greater risk of nephritis.

Further studies are needed to identify the genetic markers for HSP, in order to predict which patients will develop severe nephritis and would benefit from immunosuppressive treatment with a reduced frequency of adverse events (pharmacogenetics).

Furthermore, patients with HSP, particularly those with renal involvement, should be monitored indefinitely with renal function and urinary sediment tests. Ronkainen et al. ${ }^{23}$ studied adults after 26 years' follow-up of HSP and found evidence of delayed nephritis development in pregnancy, even among patients who had not initially presented with nephritis or developed it while in the pediatric age group.

In conclusion, renal involvement occurred in 70 (49\%) of our patients, with $6998 \%$ developing it within the first 3 months of the disease. The presence of severe abdominal pain, gastrointestinal bleeding and use of corticosteroids were associated with renal involvement in HSP by a univariate statistical analysis. However, after multivariate analysis, only severe abdominal pain remained as the only initial factor associated with the occurrence of HSP nephritis. This being so, those patients with HSP who exhibit gastrointestinal symptoms during the first 3 months should be rigorously monitored, due to the increased risk of renal involvement.

\section{Acknowledgement}

This study was supported by the Conselho Nacional de Desenvolvimento Científico e Tecnológico - CNPQ (grant number 302469/2005-2 awarded to CAAS).

\section{References}

1. Kiss MH, de Sa EG, Lotufo SA, Sogabe T, Moretto PA. Aspectos clínicos, laboratoriais e terapêuticos de 46 crianças com púrpura de Henoch-Schönlein. J Pediatr (Rio J). 1994;70:234-9.

2. Silva CA, Campos LM, Liphaus BL, Kiss MH. Púrpura de HenochSchönlein na criança e adolescente. Rev Bras Reumatol. 2000;40:128-36.

3. Silva CAA. Púrpura de Henoch-Schönlein: revisão e atualização. Rev Paul Pediatr. 2000;18:181-5.

4. Kaku Y, Nokara K, Honda S. Renal involvement in HenochSchönlein purpura: a multivariate analysis of prognostic factors. Kidney Int. 1998;53:1755-9.

5. Sano H, Izumida M, Shimizu H, Ogawa Y. Risk factors of renal involvement and significant proteinuria in Henoch-Schönlein purpura. Eur J Pediatr. 2002;161:196-201.

6. Rigante D, Candelli M, Federico G, Bartolozzi F, Porri MG, Stabile A. Predictive factors of renal involvement or relapsing disease in children with Henoch-Schönlein purpura. Rheumatol Int. 2005;25:45-8.

7. Shin JI, Park JM, Shin YH, Hwang DH, Kim JH, Lee JS. Predictive factors for nephritis, relapse, and significant proteinuria in childhood Henoch-Schönlein purpura. Scand J Rheumatol. 2006;35:56-60.

8. Koskimies O, Mir S, Rapola J, Vilska J. Henoch-Schönlein nephritis: long-term prognosis of unselected patients. Arch Dis Child. 1981;56:482-4.

9. Mills JA, Michel BA, Bloch DA, Calabrese LH, Hunder GG, Arend WP, et al. The American College of Rheumatology 1990 criteria for the classification of Henoch-Schönlein purpura. Arthritis Rheum. 1990;33:1114-21.

10. Iijima K, Ito-Kariya S, Nakamura H, Yoshikawa N. Multiple combined therapy for severe Henoch-Schönlein nephritis in children. Pediatr Nephrol. 1998;12:244-8.

11. Montaner J, Molina C, Alvarez-Sabin J, Ordi J. [Neurological manifestations of Schönlein-Henoch purpura: cerebral vasculitis or reversible posterior leukoencephalopathy syndrome?] Med Clin (Barc). 2000;115:677.

12. Mollica F, Li Volti S, Garozzo R, Russo G. Corticosteroid therapy does not prevent nephritis in Henoch-Schönlein purpura. Pediatr Nephrol. 1994;8:131.

13. Saulsbury FT. Corticosteroid therapy does not prevent nephritis in Henoch-Schönlein purpura. Pediatr Nephrol. 1993; 7:69-71. 
14. Huber AM, King J, McLaine P, Klassen T, Pothos M. A randomized, placebo-controlled trial of prednisone in early HenochSchönlein Purpura [ISRCTN85109383]. BMC Med. 2004;2:7.

15. Ronkainen J, Koskimies O, Ala-Houhala M, Antikainen M, Merenmies J, Rajantie J, et al. Early prednisone therapy in Henoch-Schonlein purpura: a randomized, double-blind, placebo-controlled trial. J Pediatr. 2006;149:241-7.

16. Saulsbury FT. IgA rheumatoid factor in Henoch-Schönlein purpura. J Pediatr. 1986;108;71-6.

17. Kauffmann RH, Herrmann WA, Meyer CJ, Daha MR, Van Es LA. Circulating IgA-immune complexes in Henoch-Schönlein purpura. A longitudinal study of their relationship to disease activity and vascular deposition of $\operatorname{IgA}$. Am J Med. 1980;69:859-66

18. O'Donoghue DJ, Jewkes F, Postlethwaite RJ, Ballardie FW. Autoimmunity to glomerular antigens in Henoch-Schoenlein nephritis. Clin Sci (Lond). 1992;83:281-7.

19. O'Donoghue DJ, Nusbaum P, Noel LH, Halbwachs-Mecarelli L, Lesavre P. Antineutrophil cytoplasmic antibodies in IgA nephropathy and Henoch-Schonlein purpura. Nephrol Dial Transplant. 1992;7:534-8.
20. Saulsbury FT. Increased serum IgD concentrations in children with Henoch-Schönlein purpura. $\mathrm{Br} J$ Rheumatol. $1998 ; 37: 570-2$.

21. Yi ZW, Fang XL, Wu XC, He XJ, He QN, Dang XQ, et al. Role of PAX2 gene polymorphisms in Henoch-Schönlein purpura nephritis. Nephrology (Carlton). 2006;11:42-8.

22. Ozkaya O, Soylemezoglu O, Gonen S, Misirlioglu M, Tuncer S, Kalman $S$, et al. Renin-angiotensin system gene polymorphisms: association with susceptibility to HenochSchönlein purpura and renal involvement. Clin Rheumatol. 2006;25:861-5.

23. Ronkainen J, Nuutinen M, Koskimies O. The adult kidney 24 years after childhood Henoch-Schönlein purpura: a retrospective cohort study. Lancet. 2002;360:666-70.

Correspondence:

Clovis Artur Almeida Silva

Rua Senador César Lacerda Vergueiro, 494/82, Vila Madalena

CEP 05435-010 - São Paulo, SP - Brazil

Tel.: + 55 (11) 3069.8675

Fax: + 55 (11) 3069.8503

E-mail: clovisaas@icr.hcnet.usp.br 